\title{
STUDI TRANSFORMASI PASAR TRADISIONAL \\ (OBJEK STUDI : PASAR KEBAYORAN LAMA, KELURAHAN KEBAYORAN LAMA UTARA, KECAMATAN KEBAYORAN LAMA, JAKARTA SELATAN)
}

\author{
Julian Martin ${ }^{1)}$, Parino Rahardjo ${ }^{2)}$, Suryadi Santoso ${ }^{3)}$ \\ 1)Program Studi S1 PWK, Fakultas Teknik, Universitas Tarumanagara, julian.martin98@yahoo.com \\ 2)Program Studi S1 PWK, Fakultas Teknik, Universitas Tarumanagara, parinor19@gmail.com \\ 3)Program Studi S1 PWK, Fakultas Teknik, Universitas Tarumanagara, josantosojkt@yahoo.com
}

Masuk: 11-08-2020, revisi: 07-09-2020, diterima untuk diterbitkan: 25-09-2020

\begin{abstract}
Abstrak
Pasar Kebayoran Lama merupakan pasar yang berdiri pada tahun 1987, dikelola oleh PD. Pasar Jaya dan Masa hak pakai Pasar Kebayoran Lama akan habis pada Maret 2022. Selama 32 tahun bangunan Pasar Kebayoran Lama berdiri, Pasar Kebayoran Lama belum pernah diperbaiki secara menyeluruh. Karakteristik di sekitar Pasar Kebayoran Lama didominasi oleh area hunian dan komersial serta berdekatan dengan moda transportasi massal. Aktivitas yang terjadi pada pasar dan sekitarnya terjadi 24 jam dalam sehari dan aktivitas kegiatan tebagi menjadi tiga lokasi berbeda yaitu dalam bangunan, sekitar tapak, dan sekitar lokasi serta pada kegiatan yang terjadi terdapat 3 pengelola yaitu PD. Pasar Jaya, RW 01, dan informal. Untuk kondisi fisik bangunan pasar sudah mengalami penurunan dari segi fungsi maupun estetika dan menyebabkan Pasar Kebayoran Lama semakin kehilangan eksistensinya. Dalam memperbaiki citra pasar tradisional maka PD. Pasar Jaya menanggapinya dengan merencanakan pengembangan Pasar yang dikaitkan dengan fungsi lain agar sesuai dengan perkembangan kota pada saat ini. Tujuan dari penelitian ini adalah Teridentifikasi Prinsip Prinsip dasar perencanaan kembali ( Redesign) Pasar Kebayoran Lama dengan memperhatikan potensi sekitar Pasar, kondisi eksisting, dan perubahan pola jual beli di Pasar Kebayoran Lama. Dalam penelitian ini digunakan pendekatan kualitatif untuk menggambarkan kondisi eksisting dan melihat perubahan yang terjadi pada Pasar Kebayoran Lama. Hasil penelitian ditemukan bahwa terdapat perubahan pola penjual dan pembeli yang bertransaksi secara grosir, dan pengunjung pasar sebagian besar berdomisili dari sekitar pasar yang membeli kebutuhan bahan pangan.
\end{abstract}

Kata kunci: aktivitas; pasar tradisional; pengembangan; revitalisasi; transformasi

\begin{abstract}
Kebayoran Lama Market is a market that build in the year 1987, managed by PD. Pasar Jaya and the rights usage life of Pasar Kebayoran Lama will be exhausted in March 2022. During 32 years old Kebayoran Market building stood, Pasar Kebayoran Lama has not been repaired thoroughly. The characteristic around Pasar Kebayoran Lama is dominated by residential and commercial area and adjacent to mass transportation mode. The activities that occur in the market and surrounding areas occur 24 hours a day and the activity of the activities to be three different locations in the building, around the site, and around the location and in the activities that occur there are 3 managers namely PD. Pasar Jaya, RW 01, and informal. For the physical condition of the market building has decreased in terms of function and aesthetics and caused Pasar Kebayoran Lama to lose its existence. In improving the image of traditional market then PD. Pasar Jaya responded by planning the market development associated with other functions to suit the development of the city at this time. The purpose of this research is to identify the basic principles of the re-planning (Redesign) Pasar Kebayoran Lama by observing the potential around the market, existing condition, and changes in the pattern of buying and selling in Kebayoran Lama market. In this study, use a qualitative approach to describe existing conditions and see the changes that occurred in Pasar Kebayoran Lama. The results of the research found that there were changes in the
\end{abstract}


pattern of sellers and buyers who transact wholesale, and the market visitors are mostly domiciled from around the market that buys the needs of groceries.

Keywords: activity; development; revitalization; traditional market; transformation

\section{PENDAHULUAN}

\section{Latar Belakang}

Pasar tradisional identik dengan kondisi pasar yang kumuh, kotor, dan bau, sehingga memberikan atmosfer yang tidak nyaman dalam berbelanja. Sedangkan pasar modern memberikan suasana berbelanja yang sebaliknya yaitu kondisi pasar yang bersih, higenis, dan harum serta dilengkapi pendingin ruangan yang memberikan atmosfer berbelanja yang nyaman. Untuk memperbaiki kelemahan dari pasar tradisional maka, dapat melihat pentingnya suatu tindakan peremajaan pasar tradisional yang selaras dengan perkembangan kota. Melalui PD. Pasar Jaya peremajaan pasar tradisional dilakukan sesuai dengan kebutuhan masyarakat dan kedepannya Perumda Pasar Jaya berencana mengembangan pasar modern sesuai dengan SNI sebagai suatu cara peremajaan pasar tradisional sedangkan untuk rencana jangka panjang yang akan diambil untuk pasar tradisional, Perumda Pasar Jaya memiliki konsep menghubungkan pasar dengan fungsi lain seperti hunian, sarana transportasi, dan area komersil. Pasar kebayoran Lama merupakan salah satu pasar tradisional yang dibangun pada tahun 1987 dengan luas lahan $8.775 \mathrm{~m}^{2}$ dan memiliki luas bangunan $11.628 \mathrm{~m}^{2}$. Pasar Kebayoran Lama di kelola oleh PD. Pasar Jaya dengan masa Hak Pakai 1 April 2007 sampai dengan 31 Maret 2022 dengan jumlah tempat usaha sebanyak 1071 dan tingkat Occupancy rate 78\%. Karakteristik di sekitar Pasar Kebayoran Lama didominasi oleh area komersial dan hunian. Pasar Kebayoran Lama juga berdekatan dengan moda transportasi massal yaitu Stasiun KRL Kebayoran dengan jarak $\pm 150 \mathrm{~m}$ dan Jumlah penumpang pada Stasiun Kebayoran pada tahun 2014 adalah sebanyak 8.000-11.000 orang/hari.

\section{Rumusan Masalah}

Pasar Kebayoran Lama merupakan salah satu pasar terbesar di Jakarta Selatan yang dikelola oleh PD. Pasar Jaya dan memiliki klasifikasi kelas Pasar A, Pasar Kebayoran Lama telah berdiri sejak tahun 1987. Masa hak pakai Pasar Kebayoran Lama akan habis pada 31 Maret 2022 sehingga PD. Pasar Jaya memerlukan perpanjangan izin dan PD. Pasar Jaya sedang berupaya melakukan perubahan izin menjadi Hak Pengelolaan Lahan. Kedepannya PD. Pasar Jaya memiliki visi melakukan pengembangan/peremajaan dengan konsep property baru yang berbasis pasar yang selaras dengan perkembangan kota Jakarta. Kondisi fisik Pasar Kebayoran Lama sudah mulai mengalami penurunan dan pada Pasar kebayoran terjadi perubahan aktivitas dan adanya perubahan pola penjual dan pembeli dengan karakter bukan hanya penggunaan individu namun sebagai pelaku usaha.

\section{Tujuan}

Teridentifikasinya prinsip-prinsip dasar pengembangan kembali Pasar Kebayoran Lama dengan mempertimbangkan transformasi/perubahan yang terjadi pada Pasar Kebayoran Lama, namun dapat menanggapi perubahan prilaku konsumen yang sesuai dengan perkembangan Kota Jakarta secara umum.

\section{KAJIAN LITERATUR}

Pasar merupakan tempat bertemunya penjual dan pembeli serta ditandai dengan adanya transaksi penjual pembeli secara langsung dan biasanya ada proses tawar-menawar, bangunan biasanya terdiri dari kios-kios atau gerai, los dan dasaran terbuka yang dibuka oleh penjual maupun suatu pengelola pasar (Malono, 2011). Pasar Jaya adalah Perusahaan Daerah milik Pemerintah Provinsi DKI Jakarta yang melaksanakan pelayanan umum dalam bidang pengelolaan area pasar, membina pedagang pasar, ikut membantu stabilitas harga dan kelancaran distribusi barang dan jasa (PD. Pasar Jaya).

Pasar Informal, istilah sektor informal biasanya digunakan untuk menunjukkan sejumlah kegiatan ekonomi yang berskala kecil. Tetapi akan menyesatkan bila disebutkan perusahaan berskala kecil, 
karena sektor informal dianggap sebagai suatu manifestasi situasi pertumbuhan kesempatan kerja di negara sedang berkembang, karena itu mereka yang memasuki kegiatan berskala kecil ini di kota, terutama bertujuan untuk mencari kesempatan kerja dan pendapatan dari pada memperoleh keuntungan (Alma.B, 2011).

Pasar modern adalah suatu pasar dimana pembeli dan penjualnya tidak melakukan transaksi secara langsung. Pembeli hanya melihat label harga pada suatu kemasan produk dan pembeliannya dilayani secara mandiri oleh pramuniaga contohnya supermarket, minimarket, hipermarket dsb (Hurtabarat, 2009).

Revitalisasi adalah upaya untuk memvitalkan kembali suatu kawasan atau bagian kota yang dulunya pernah vital/hidup, akan tetapi kemudian mengalami kemunduran/degradasi. Skala revitalisasi ada tingkatan makro dan mikro. Proses revitalisasi sebuah kawasan mencakup perbaikan aspek fisik, aspek ekonomi dan aspek sosial. Pendekatan revitalisasi harus mampu mengenali dan memanfaatkan potensi lingkungan (sejarah, makna, keunikan lokasi dan citra tempat) (Danisworo, 2002). Redevelopment atau pembangunan kembali adalah upaya penataan kembali suatu kawasan kota dengan terleboh dahulu melakukan pembongkaran sarana atau prasarana dari sebagian atau seluruh kasawan kota tersebut (Zahnd, 2006).

\section{METODE}

Metode penelitian dalam penelitian ini menggunakan pendekatan kualitatif dimana penulis menemukan masalah setelah melakukan survey langsung dan mendapatkan data lapangan. Lokasi penelitian ini berada di Kota Jakartarta Selatan, tepatnya di Pasar Kebayoran Lama Jl. Raya Kebayoran Lama, RT.1/RW.2, Kelurahan Kebayoran Lama Utara, Kecamatan Kebayoran Lama. Penulis menggunakan data primer yang diperoleh secara langsung dan data sekunder secara tidak langsung melalui media penghubung. Teknik pengumpulan data yang dilakukan penulis adalah dengan cara melakukan wawancara dengan stakeholder terkait yang dianggap berpengaruh dalam kegiatan pasar. Stakeholder terkait tersebut antara lain adalah pengelola Pasar Kebayorran Lama, Divisi Perencanaan PD. Pasar Jaya, pedagang dan pembeli di Pasar Kebayoran Lama serta PKL disekitar lokasi Pasar Kebayoran Lama. Untuk memperoleh data kondisi eksisting Pasar Kebayoran Lama penulis melakukan survey lapangan serta penulis juga mengumpulkan data data pendukung melalui dokumentasi atau arsip dari PD. Pasar Jaya dan media elektronik. Analisis yang digunakan dalam penelitian ini antara lain analisis kebijakan, analisis lokasi, analisis tapak, analisis kondisi bangunan , analisis aktivitas, analisis transformasi, serta analisis studi banding.

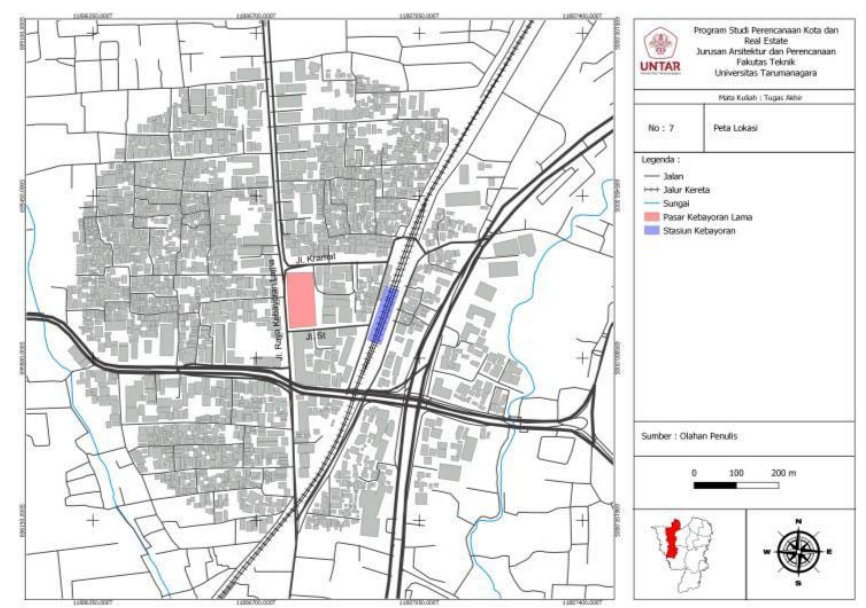

Gambar 1. Lokasi Penelitian

Sumber: olahan penulis 2019 


\section{DISKUSI DAN HASIL}

Pasar Kebayoran Lama berada di Jalan Raya Kebayoran Lama, Kelurahan Kebayoran Lama Utara, Kecamatan Kebayoran Lama, Kota Jakarta Selatan. Berikut ini merupakan profil umum dari Pasar Kebayoran Lama.

Tabel 1. Profil Objek Studi

\begin{tabular}{ll}
\hline Pengelola & PD. Pasar Jaya \\
\hline Kategori Pasar & A \\
\hline Luas Lahan & $8.775 \mathrm{~m}^{2}$ \\
\hline Luas Bangunan & $11.268^{2}$ \\
\hline Luas Parkir & $917,30 \mathrm{~m}^{2}$ \\
\hline Masa Hak Pakai & 01 April 2007 s.d 31 Maret 2022 \\
\hline Ketinggian & 2 Lantai \\
\hline Jumlah Tempat Usaha & 1071 \\
\hline
\end{tabular}

Sumber: Kantor Pengelola Pasar Kebayoran Lama, 2019

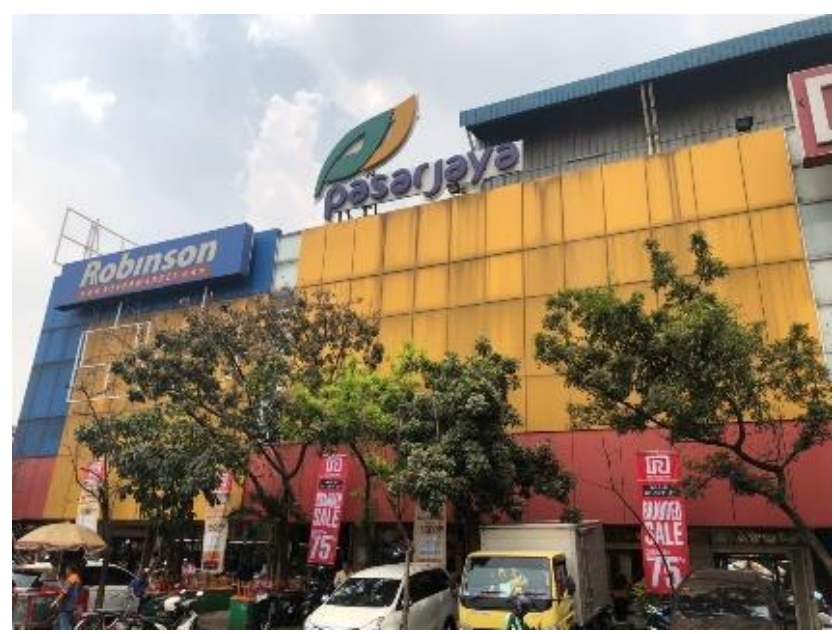

Gambar 2. Tampak Depan Pasar Kebayoran Lama Sumber: Dokumentasi penulis, 2019

\section{Occupancy Rate dan Jenis Jualan}

Pasar Kebayoran Lama adalah pasar dengan lingkup pelayanan kota dengan jumlah lantai sebanyak 2 Lantai, 836 tempat usaha aktif, 235 tempat usaha tidak aktif. Presentase jumlah tempat usaha aktif adalah $78 \%$ sedangkan yang tidak aktif sebanyak $22 \%$.

Tabel 2. Jenis Jualan di Pasar

\begin{tabular}{lccc}
\hline Tempat Usaha & Lt dasar & Lt 1 & Total \\
\hline Toko Emas & 30 & 0 & 30 \\
\hline Textile & 142 & 0 & 142 \\
\hline Kelontong & 58 & 81 & 139 \\
\hline Bahan Pangan & 202 & 266 & 468 \\
\hline Barang Teknik & 5 & 5 & 10 \\
\hline Restoran/Warung Makan & 0 & 45 & 45 \\
\hline Ramayana & 0 & 1 & 1 \\
\hline Robinsons Supermarket & 0 & 1 & 1 \\
\hline Kosong & 58 & 177 & 235 \\
\hline Total & 495 & 576 & 1071 \\
\hline
\end{tabular}

Sumber: Olahan penulis, 2020 


\section{Tingkat Hunian Pasar Kebayoran Lama}

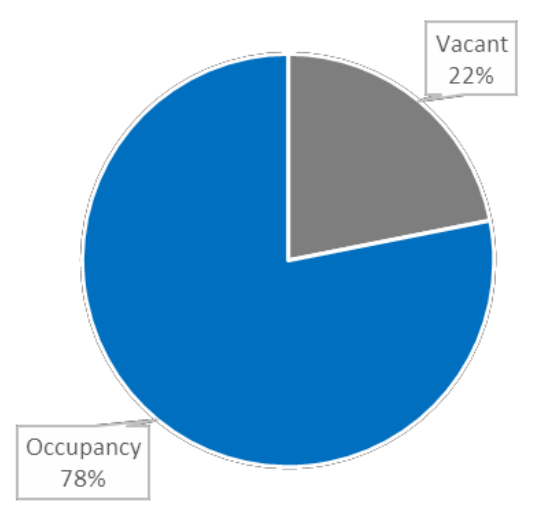

Gambar 3. Occupancy Rate Pasar Kebayoran Lama Sumber : Olahan Penulis, 2019

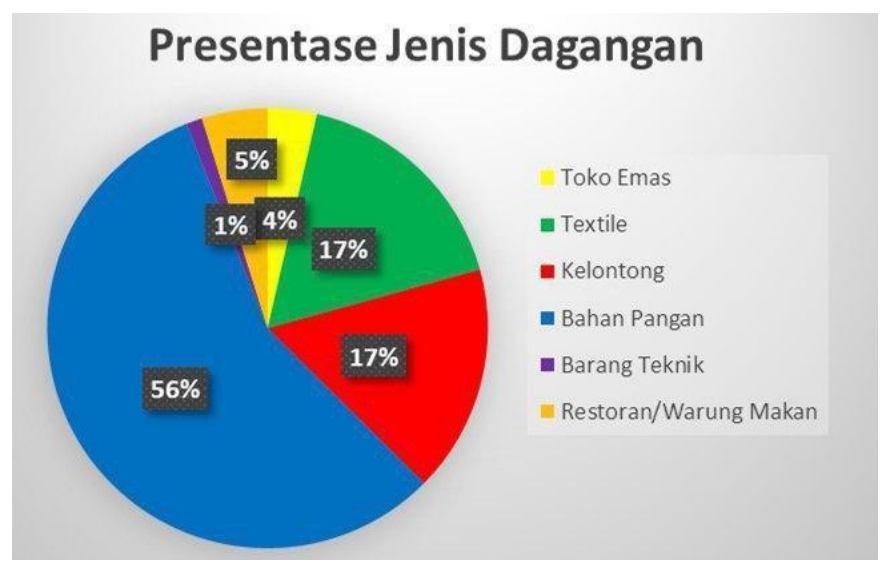

Gambar 4. Persentase Jenis Dagangan

Sumber: Olahan penulis, 2019

Berdasarkan hasil survey, lantai dasar adalah lantai teramai dan tingkat hunian tertinggi. Pada lantai dasar jenis jualan terbanyak adalah bahan pangan dan textile. Pada lantai 1 merupakan lantai yang tempat usahanya paling banyak tidak aktif, pada lantai satu jenis jualan terbanyak adalah bahan pangan yang umumnya menjual bahan pangan basah seperti daging, ayam, ikan dan bumbu dapur yang telah di olah.

\section{Kondisi Eksisting Fasilitas Umum dan Bangunan Pasar}

Dengan tersedianya fasilitas umum di Pasar Tradidisional maka dapat menunjang aktivitas yang ada di pasar, karena itu saat melakukan pembangunan/ revitalisasi pasar harus memenuhi standar fasilitas yang telah ditentukan dalam SNI Pasar Rakyat. Pada kondisi eksisting Pasar Kebayoran Lama terdapat banyak fasilitas umum di Pasar Kebayoran Lama yang masih belum sesuai dengan SNI Pasar Rakyat 8152-2015 seperti tidak memiliki pos keamanan, pos kesehatan, area penghijauan, ruang bersama, ruang menyusui, tempat cuci tangan, CCTV, dll. Untuk fasilitas pada Pasar Kebayoran Lama memiliki 1 musholla dan memiliki 2 toilet di lokasi yang berbeda dengan ruang pria dan wanita terpisah. Sedangkan kondisi eksistingnya mulai menurun seperti hydran yang mulai rusak di setiap lantainya, dan eksterior dan interior bangunan sudah mulai rusak. 

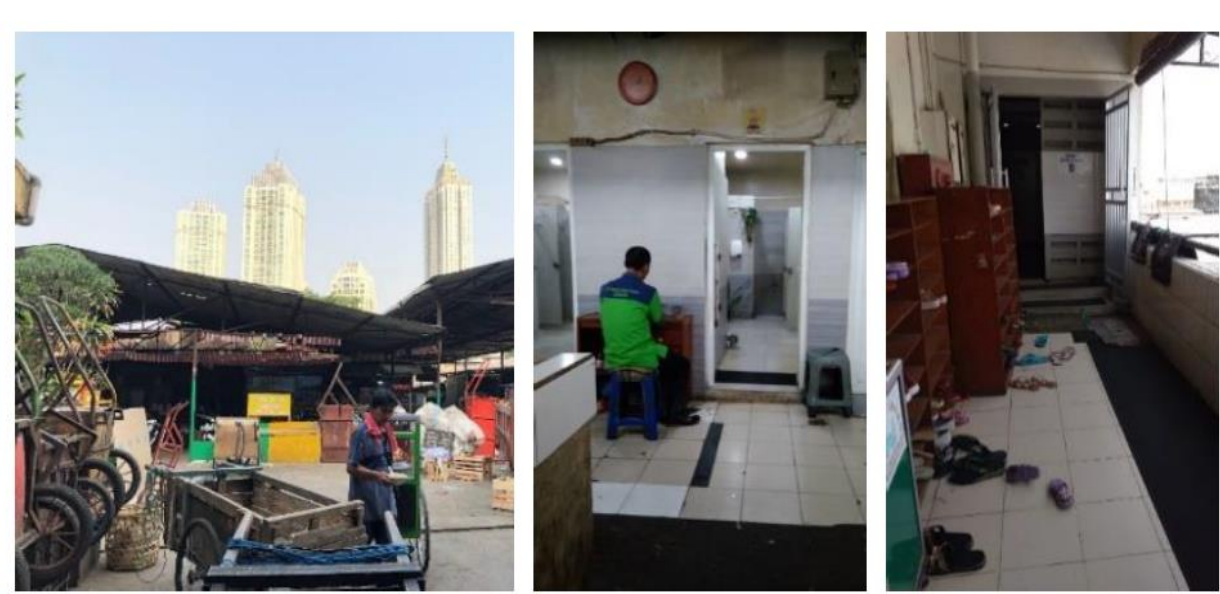

Gambar 5. Kondisi Eksisting Fasilitas Pasar Kebayoran Lama

Sumber: Dokumentasi penulis, 2019

\section{Masa Pakai Pasar hasil dan Rencana PD.Pasar Jaya}

Masa hak pakai dari Pasar Kebayoran Lama akan habis pada Maret 2020 maka dari itu PD. Pasar Jaya memiliki 2 rencana yaitu rencana jangka panjang dan jangka pendek. Untuk rencana jangka pendeknya, PD. Pasar Jaya berencana mengubah Pasar Kebayoran Lama menjadi pasar bersih dan retail. Sedangan untuk rencana jangka panjangnya, PD. Pasar Jaya berencana menjalin kerja sama dengan pihak ketiga dalam bentuk kerja sama pengelolaan dan pembangunan, untuk pengembangan pasar akan dikembangkan dengan memadukan pasar dengan fungsi lain yang berkonsep Integrated Market System. Pasar dapat dipadukan dengan properti lain seperti rusun, hunian kelas menengah, moda transportasi massal. Pengembangan tersebut dilakukan karena PD. Pasar Jaya melihat potensi serta kebutuhan dari masyarakat Kota Jakarta diharapkan dapat menjadi solusi pengoptimalan fungsi pasar yang sesuai dengan perkembangan kota pada saat ini. Pada RTDR DKI Jakata kedepannya Pasar Kebayoran Lama direncanakan sebagai zona ungu atau zona perdagangan dan jasa, hal tersebut tentu saja terdapat ketidak sesuaian rencana dengan PD. Pasar Jaya yang menginginkan mixuse.
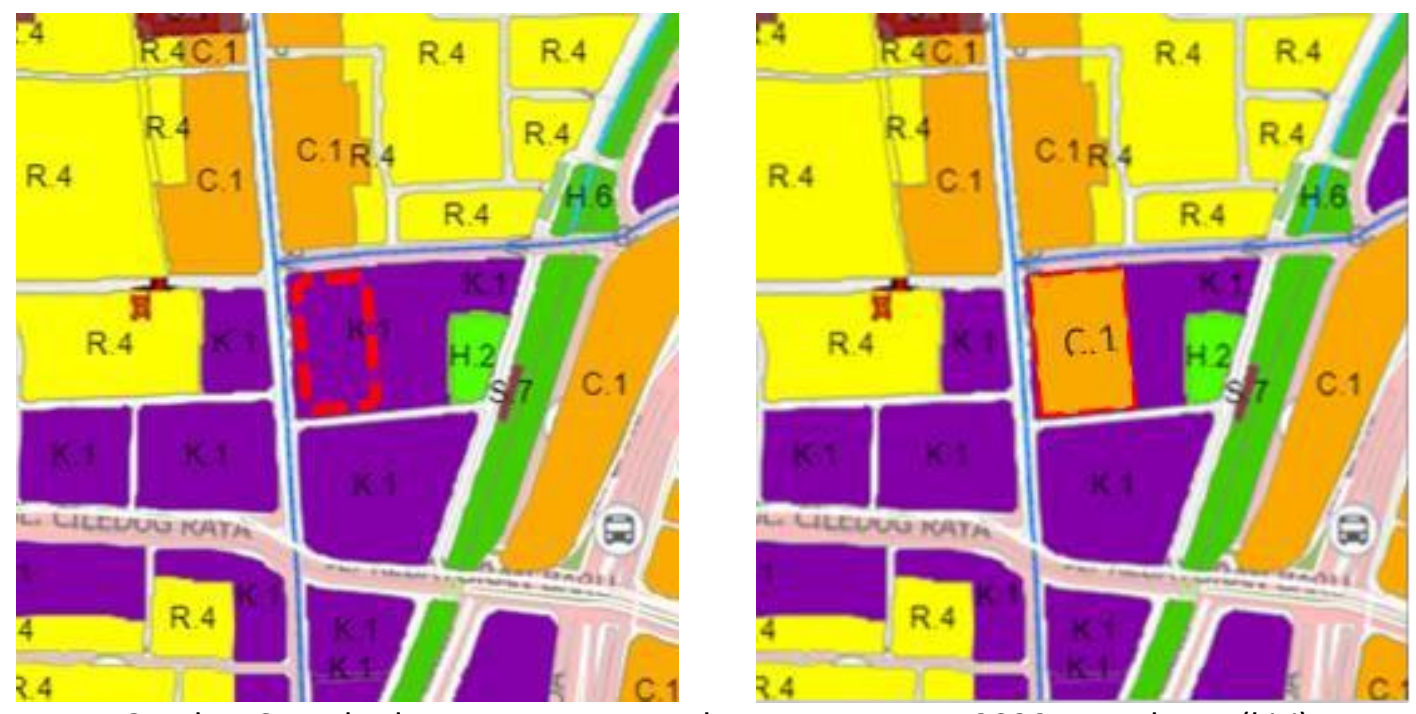

Gambar 6. Perbedaan Penggunaan Lahan antara RDTR 2030 DKI Jakarta (kiri) dengan Rencana PD. Pasar Jaya (kanan)

Sumber: jakartasatu.jakarta.go.id, diolah penulis, 2020

\section{Perubahan Aktivitas Pasar}

Kegiatan yang terjadi di Pasar Kebayoran Lama dan sekitarnya terjadi selama hampir 24 jam dalam sehari dan kegiatan pasar tidak hanya terjadi di dalam bangunan Pasar Kebayoran Lama saja namun terdapat 3 lokasi kegiatan yang berbeda yaitu dalam bangunan pasar, sekitar tapak pasar, dan sekitar 
lokasi pasar. Tiap lokasi kegiatan terbagi penggunaan ruang dan fungsinya berdasarkan waktu dan jam tertentu. Pada dalam bangunan pada dini hari umumnya menjual bahan pangan basah, pada siang hari berjualan bahan pangan kering dan textile. Pada sekitar tapak saat dini hari PKL binaan umumnya menjual sayuran dan bumbu dapur namun pada siang hari PKL binaan berganti menjadi PKL binaan textile dan pada malam hari kembali ditempati PKL binaan sayuran. Sedangkan pada sekitar lokasi PKL yang berjualan juga menyesuaikan jam dan kebutuhan dari masyarakat yang berbelanja. Sehingga tiap lokasi dan tiap waktu terlihat penggunaan ruang dan jenis jualannya.
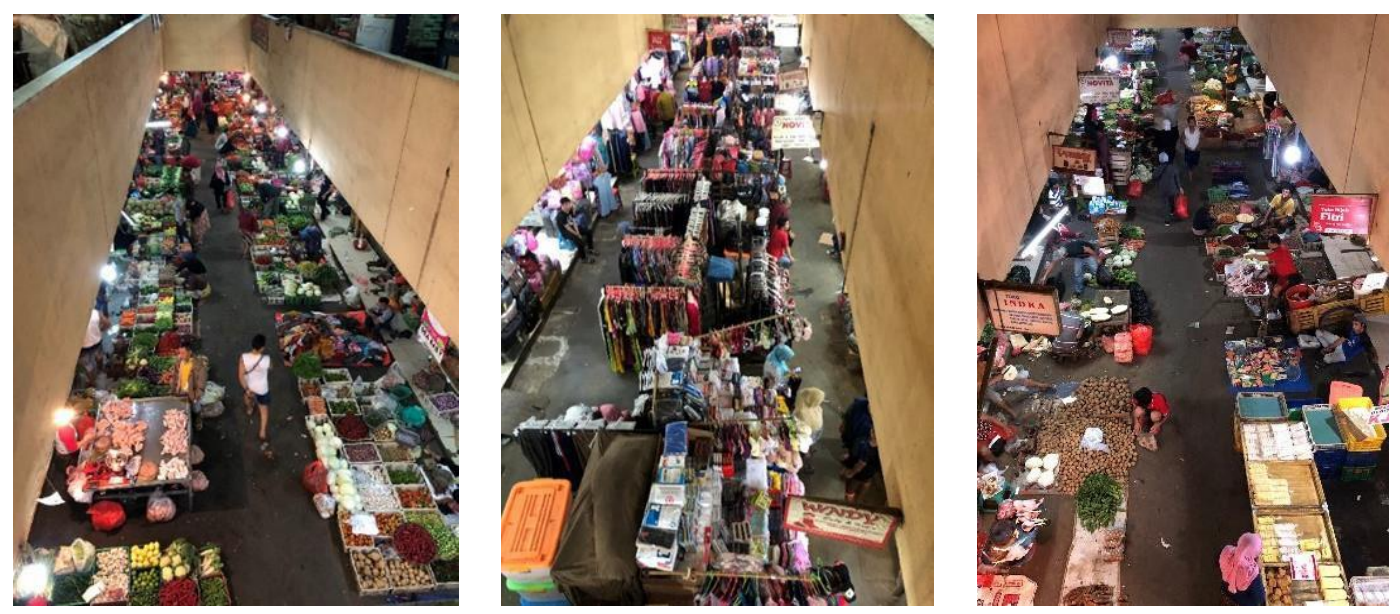

Gambar 7. Aktivitas Sekitar Tapak Pasar Kebayoran Lama Pada Dini Hari (kiri), Siang Hari (tengah) dan Malam Hari (kanan)

Sumber: Dokumentasi penulis, 2020

\section{Karakteristik Pasar dan Aksesbilitas}

Karakteristik di sekitar Pasar Kebayoran Lama penggunaan lahannya di dominasi oleh komersial, campuran, dan hunian. Untuk penggunaan lahan campuran sebagian besar berbentuk ruko yang berjualan elektronik, perabotan dan perhiasan, sedangkan untuk penggunaan lahan hunian didominasi oleh perumahan swadaya dan apartement dengan kelas menengah atas. Keberadaan area komersial disekitar Pasar Kebayoran Lama membuat sekitar lokasi pasar menjadi ramai dan aktivitasnya terjadi hampir 24 jam dalam sehari. Pasar Kebayoran Lama berdekatan dengan Stasiun KRL Kebayoran dengan jarak \pm 150 dan waktu tempuh \pm 5 min serta berdekatan dengan Halte Transjakarta Ps. Kebayoran Lama dengan jarak $\pm 500 \mathrm{~m}$ dan waktu tempuh $\pm 10 \mathrm{~min}$. untuk angkutan umum terdapat 6 rute yang melalui Pasar Kebayoran Lama. dengan dilayaninya trasnportasi umum dan angkutan massal membuat Pasar Kebayoran Lama dapat semakin mudah di akses.

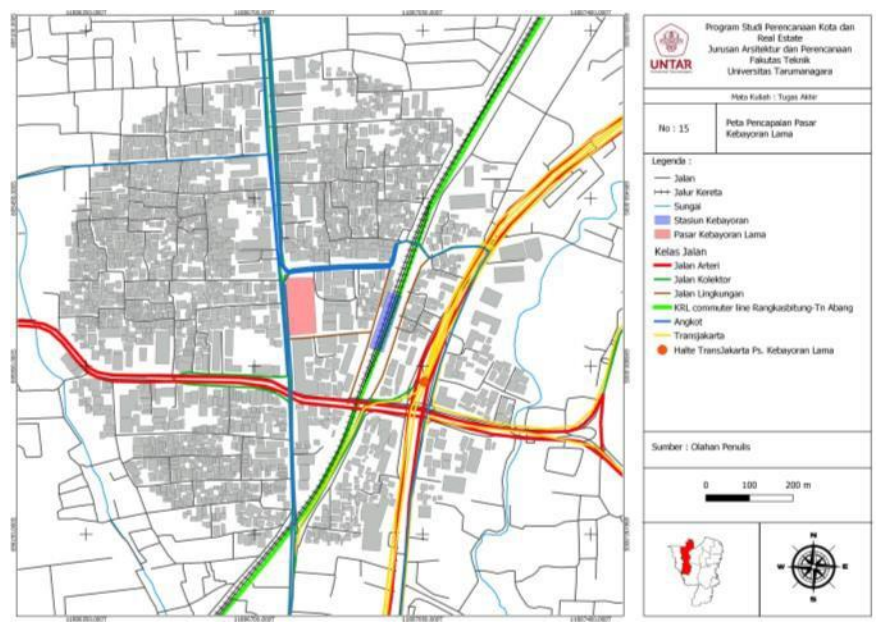

Gambar 8. Aksesibilitas Pasar Kebayoran Lama Sumber: Olahan penulis, 2019 


\section{Terjadi perubahan Pola Jual Beli di Pasar Kebayoran Lama}

Berdasarkan penelitian penulis di Pasar Kebayoran Lama terjadi adanya perubahan pola penjual dan pembeli yang berbelanja. Sebelumnya orang berbelanja di pasar tradisional untuk memenuhi kebutuhan sehari-hari dan pedagang menjual untuk memenuhi kebutuhan sehari- hari masyarakat, kini terdapat pembeli yang berbelanja secara grosir untuk dijual atau di olah kembali seperti pelaku usaha/penjual (reseller) yang berbelanja secara grosir kemudian dijual kembali secara ecer. Jenis jualan yang paling sering dibeli adalah jenis jualan bahan pangan seperti daging, ayam, ikan, sayuran, bumbu dapur yang telah di olah, sayuran dan sembako. Umumnya transaksi secara grosir terjadi pada malam hingga dini hari dan pembeli yang berbelanja sebagian besar berdomisili di sekitar Pasar Kebayoran Lama ( Kebayoran Lama, Ciledug, Ciputat, Cipulir, Bintaro) dengan membawa kendaraan pribadi, pembeli dapat berbelanja di 3 lokasi yang berbeda sesuai dengan kebutuhan dari pembeli tersebut.
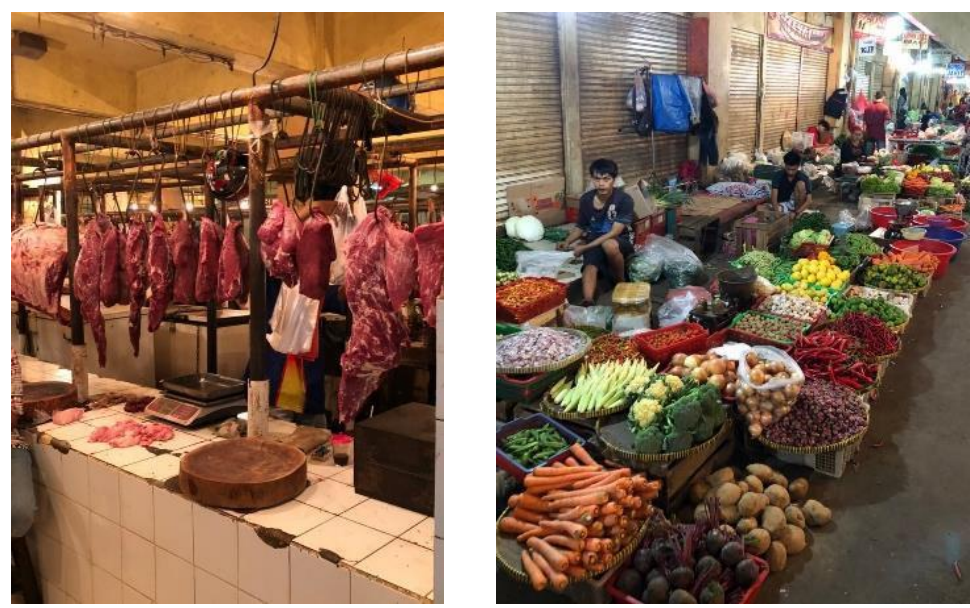

Gambar 9. Pedagang Penjual Daging (kiri) dan Sayuran (kanan) di Pasar Kebayoran Lama Sumber: Dokumentasi penulis, 2020

\section{Tidak ada Koordinasi antara pengelola Pasar Kebayoran dan Pengelola PKL Sekitar Lokasi}

Pasar Kebayoran Lama yang aktivitasnya begitu ramai dan aktivitas kegiatanya terbagi menjadi 3 lokasi yang berbeda membuat adanya pengelolaan yang berbeda juga. Pada dalam bangunan dan sekitar tapak pengelolaan dikelola oleh PD Pasar Jaya, pedagang dan PKL binaan membayar tariff sewa kepada PD. Pasar Jaya sesuai dengan tariff jenis jualan yang berlaku, sedangkan pada sekitar lokasi terdapat PKL informal tanpa pengelola yang berada di badan jalan, mereka membayar uang kebersihan Rp. 3.000 - Rp. 5.000 kepada petugas kebersihan, uang listrik sebesar Rp. 30.000/hari ke RW01 dan uang keamanan kepada preman setempat sesuai dengan kesepakatan. Pada sekitar lokasi terdapat area berjualan yang dikelola oleh RW01 tepat ya dibagian sisi Timur Pasar Kebayoran Lama. Untuk area yang dikelola oleh RW01 memiliki tarif sekitar Rp 20.000/ hari, Rp 675.000/bulan, dan Rp 14 juta/tahun tentunya tariff tersebut variatif tergantung tempat, lokasi, luas dan kesepakatan dengan kepala RW 01. Lapak dagangan ditempatkan dibawah atap dengan system terbuka tanpa sekat dengan lapak dagangan juga bersifat semi permanent (tikar, meja kayu/gerobak). Terdapatnya 3 pengelolaan yang berbeda di Pasar Kebayoran Lama membuat Pasar Kebayoran Lama menjadi tidak teratur dan semakin semrawut. menurut wawancara penulis dengan pengelola RW01 mengatakan bahwa tidak ada bentuk kerja sama maupun rencana dengan PD. Pasar Jaya / Pemda kedepannya. 


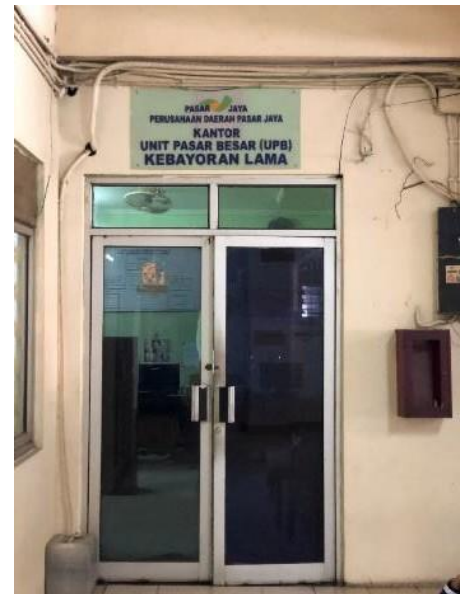

Pengelola PD Pasar Jaya

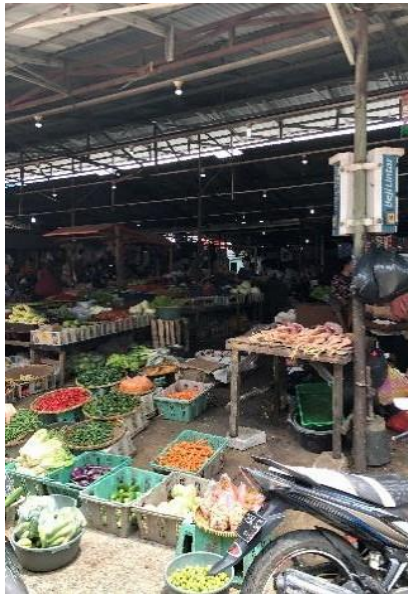

Pengelola RW 01

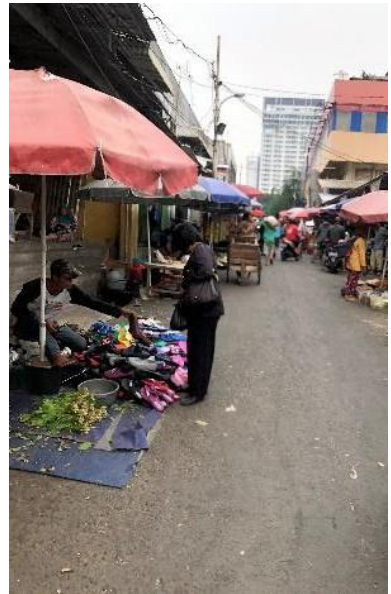

Tanpa Pengelola

Gambar 10. Pengelola yang Ada di Pasar Kebayoran Lama dan Sekitar Sumber: Dokumentasi Penulis, 2020
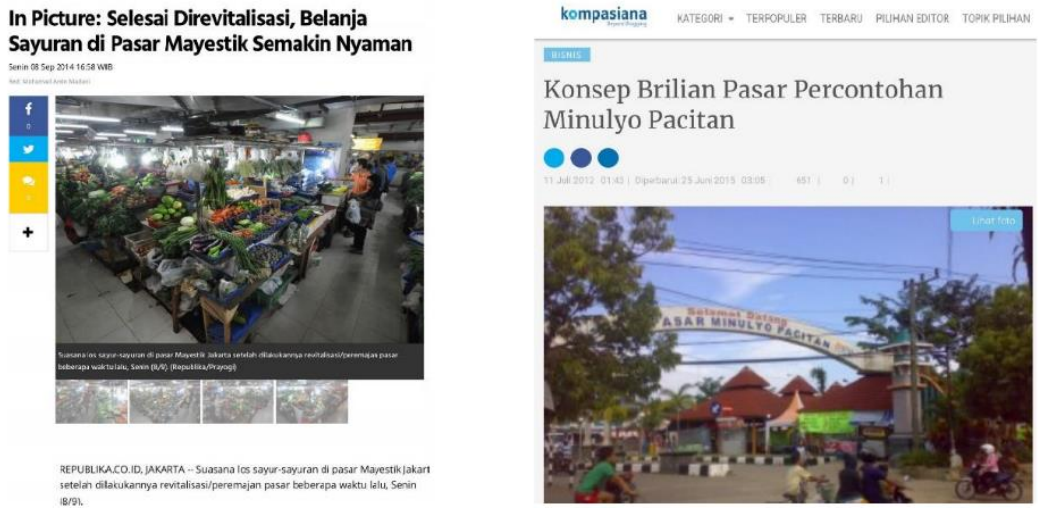

Gambar 11. Pasar yang Menjadi Studi Banding Sumber: Google Image, 2020

\section{Studi Banding}

Pasar Mayestik Jakarta Selatan di revitalisasi/peremajaan pada tahun 2010 dengan seluas $6.905 \mathrm{~m}^{2}$ dan ketinggian bangunan sebanyak 7 lantai. Pasar Mayestik di revitalisasi dengan konsep modern dan dilengkapi fasilitas berstandard SNI Pasar Rakyat. Pada lantai basement ditempatkan jenis jualan bahan pangan sedankan untuk lantai 1 keatas ditempatkan area textile. Keunikan pasar mayestik adalah pada lantai dasar karena adanya Citywalk yang terdapat area foodcourt yang menyediakan café dengan kursi-kursi santai sehingga membuat pengunjung menjadi nyaman dan memiliki kesan berada dalam sebuah Mall. Sedangkan pada Pasar Minulyo Pacitan menggunakan konsep tradisional-modern dengan dilengkap fasilitas yang memadai serta lahan parkir yang luas dan dapat diubah menjadi ruang publik terbuka dengan pendekatan budaya yang dapat digunakan sebagai ruang kegiatan seni kebudayaan dan hiburan seperti menggelar pameran seni, lomba, dan wisata kuliner. Pasar Minulyo semakin menarik karena menggabungkan PKL Pacitan kemudian direlokasi oleh pemda Pacitan ke komplek Pasar Minulyo dengan tujuan mengurangi dampak negatif PKL. PKL yang direkolasi diberikan tempat khusus sehingga penataannya terlihat rapih dan teratur. Setelah melihat pasar pasar tersebut, terdapat beberapa hal yang dapat di pelajari dan diterapkan dari studi banding ini untuk pada Pasar Kebayoran Lama. konsep pasar dapat di ubah menjadi tradisional-modern sehingga pola jual beli yang terjadi seperti pasar tradisional namun kondisi pasar seperti pasar modern yang membuat pengunjung lebih nyaman dan aman.

Kelengkapan fasilitas umum yang ada harus sesuai dengan SNI pasar rakyat, dalam melakukan pengembangan/revitaliasi Pasar harus dapat mengatur penzonaan berdasarkan jenis jualan dan 
mempertimbangkan kebutuhan baik dari sisi pedagang dan pembeli agar sesuai dengan kebutuhan mereka. Dan dari pengelolaan dapat mengedukasi/membina pedagang dan pembeli yang ada. Seperti membina pedagang agar dapat efisien dalam meletakan stock/barang dagangan, memilah persampahan, dan mengenalkan dengan perkembangan teknologi seperti pembayaran non tunai. Sedangkan untuk pengunjung dapat di edukasi juga seperti melakukan pembayaran non tunai dan membawa kantong belanja ramah lingkungan.

Tabel 3. Hasil Studi Banding Pasar

\begin{tabular}{|c|c|c|c|}
\hline & Pasar Kebayoran Lama & Pasar Mayestik & Pasar Minulyo \\
\hline Konsep Pasar & Tradisional & Modern. & Tradisional-Modern. \\
\hline Fasilitas & $\begin{array}{l}\text { Fasilitas belum memadai dan } \\
\text { belum sesuai dengan SNI. }\end{array}$ & Fasilitas sudah berstandard SNI. & Fasilitas sudah memadai. \\
\hline $\begin{array}{l}\text { Pendekatan } \\
\text { Fisik } \\
\text { Bangunan }\end{array}$ & $\begin{array}{l}\text { Bangunan Tradisional dan belum } \\
\text { pernah di revitalisasi secara } \\
\text { menyeluruh. Untuk kondisinya } \\
\text { sudah mulai menurun. }\end{array}$ & $\begin{array}{l}\text { Bangunan modern seperti pusat } \\
\text { perbelanjaan modern. Jenis } \\
\text { jualan terbagi berdasarkan lantai. }\end{array}$ & $\begin{array}{l}\text { Bangunan tradisional- } \\
\text { modern dengan system } \\
\text { pasar bersifat terbuka. }\end{array}$ \\
\hline Pengelolaan & $\begin{array}{l}\text { Tidak terdapat koordinasi antara } \\
\text { stakeholder terkait. }\end{array}$ & $\begin{array}{l}\text { Dikelola oleh PD. Pasar Jaya dan } \\
\text { sudah terdapat koordinasi } \\
\text { dengan pedagang sekitar } \\
\text { seheingga menjadi kawasan } \\
\text { perdagangan }\end{array}$ & $\begin{array}{l}\text { Dikelola oleh Pemerintah } \\
\text { Kabupaten Pacitan. } \\
\text { Terdapat koordinasi dengan } \\
\text { PKL yan telah di relokasi. }\end{array}$ \\
\hline
\end{tabular}

Sumber: olahan penulis, 2020

\section{Rekomendasi}

Pendekatan non fisik dapat dilakukan dengan cara membina atau mengedukasi pedagang dan pembeli. Pedagang dapat teratur dalam menempatkan barang dagangan dengan baik dan benar, persampahan yang sudah terpilah, dan mengedukasi pedagang agar dapat mengikuti perkembangan teknologi seperti pembayaran digital/non tunai. Sedangkan untuk pembeli dapat diedukasi juga seperti melakukan transaksi secara non tunai dan membawa tas belanja ramah lingkungan. Pendekatan fisik juga harus dilakukan dengan cara membuat bangunan pasar menjadi lebih modern berstandard SNI agar dapat menghilangkan citra pasar tradisional yang kumuh, jorok, becek, dan bau. Serta dapat Memanfaatkan dan memaksimalkan potensi yang ada disekitar lokasi seperti berdekatan dengan moda transportasi massal yaitu Stasiun KRL yang dapat dikoneksikan dengan Pasar Kebayoran Lama dan revitalisasi sosisal budaya dengan tujuan peningkatan interaksi sosial budaya antar stakeholders untuk berkoordinasi dengan pengelola RW 01 dan PKL liar agar dapat lebih teratur dan optimal.

\section{KESIMPULAN DAN SARAN}

\section{Kesimpulan}

Masa hak pakai Pasar Kebayoran Lama akan habis pada Maret 2022 dan PD. Pasar Jaya memiliki konsep rencana pengembangan menggabungkan pasar dengan fungsi lain namun untuk penerapan konsep tersebut di Indonesia belum ada yang terbukti dapat menyelesaikan masalah yang ada, tetapi tidak menutup kemungkinan bahwa konsep tersebut dapat berhasil dengan memanfaatkan pontensi disekitarnya secara hati-hati dan tepat sasaran. Pada Pasar Kebayoran Lama terjadi perubahan pola penjual dan pembeli yang berbelanja pada pasar tradisional, umumnya bertransaksi secara grosir pada malam hingga dini hari, sedangkan pada pagi hingga siang hari umumnya transaksi yang terjadi merupakan kegiatan memenuhi kebutuhan sehari-hari. Untuk pengunjung Pasar Kebayoran Lama sebagian besar bertempat tinggal disekitar Pasar Kebayoran Lama dan mereka dapat berbelanja pada 3 lokasi yaitu dalam bangunan pasar, sekitar tapak pasar, dan sekitar lokasi pasar. Kebutuhan yang paling sering sering dibeli adalah kebutuhan bahan pangan, sedangkan jenis dagangan yang paling banyak dijual di Pasar Kebayoran Lama adalah jenis dagangan bahan pangan. Terdapat perbedaan pengelolaan pada lokasi berjualan. Pada lokasi dalam bangunan dan sekitar tapak dikelola oleh PD. Pasar Jaya. Sedangkan pada sekitar lokasi terdapat 2 jenis PKL yaitu PKL yang berjualan pada tempat khusus yang dikelola oleh RW 01 dan PKL yang berjualan pada badan jalan tanpa pengelola resmi. 
ketiga pengelolaan tersebut tidak memiliki koordinasi dan kerja sama dalam bentuk apapun sehingga membuat penjual tidak atur dan menimbukan kesan kesemrawutan pada Pasar Kebayoran Lama.

\section{Saran}

Rekomendasi untuk penelitian selanjutnya, dikarenakan keterbatasan peneliti selama melakukan penelitian ini. Penelitian ini akan semakin valid apabila dilakukannya wawancara mendalam kepada stakeholders terkait (Pengelola, Penjual, Pedagang) dan menyebarkan kuesioner kepada penjual dan pengunjung, namun dikarenakan pada saat penulis melakukan penelitian dalam kondisi pandemik, sehingga penulis mengalami kesulitan dalam melakkan metode tersebut.

Rekomendasi kebijakan untuk konsep yang akan di kembangkan PD. Pasar jaya dengan mengubah pasar kemudian dikaitkan dengan fungsi lain perlu di kaji ulang dengan mempertimbangkan kepentingan dan kebutuhan dari penjual dan pembeli yang ada, sehingga konsep/kebijakan yang akan dilakukan sesuai dan tepat sasaran utuk kebutuhan masyarakat yang melakukan kegiatan di Pasar Kebayoran Lama.

\section{REFERENSI}

Alma, B. (2011). Pengantar Bisnis. Bandung: Alfabeta.

Danisworo. (2002). Revitalisasi Kawasan Kota. Jakarta.

Hurtabarat, R. (2009). Dampak Kehadiran Pasar Modern Brastagi Supermarket Terhadap Pasar Sei Si Kambing di Kota Medan. Medan.

Malono, H. (2011). Selamatkan Pasar Tradisional. Jakarta: PT.Gramedia Pustaka Umana.

Pasar Jaya, PD. (n.d.). Jakarta. Retrieved oktober 17, 2019, from http://pasarjaya.co.id/about/detail/Tentang-Kami

Zahnd, M. (2006). Perencanaan Kota Secara Terpadu. Yogyakarta: Penerbit Kanisius. 
